Journal of Teacher Education for Sustainability, vol. 17, no. 1, pp. 5-22, 2015

\title{
The Dispositions, Abilities and Behaviours (DAB) Framework for Profiling Learners' Sustainability Competencies in Higher Education
}

\author{
Frida Besong and Charlotte Holland \\ Dublin City University, Ireland
}

\begin{abstract}
The concepts of sustainability and sustainability competence are controversial, complex, difficult to define and measure, and have varied meanings for different people and practices. Given the complex nature of sustainability, there is limited availability of paradigmatic frameworks to guide educators in assessing sustainability competencies. This paper introduces the Dispositions, Abilities and Behaviours (DAB) framework, which influenced the design of an intervention in 2013-2014 that profiled sustainability competencies among final year undergraduate students in a higher education institution. The results of the mixed methods study indicate that the DAB framework has good potential as a guide to educators or researchers in understanding and profiling sustainability-related abilities, attitudes and actions (areas of performance) of cohorts of students within higher education settings.
\end{abstract}

Keywords: higher education, sustainability, sustainability competencies, dispositions, abilities, behaviours

\section{Profiling Sustainability Competencies}

The purpose of integrating sustainability in higher education programmes is to enable students to improve the quality of life on this planet while building fair, equitable and just futures for all. To effectively do this, the knowledge, skills and dispositions of higher education students need to be re-oriented towards sustainability. Sustainability competencies are reflected in the way students make sense of our complex world, through their attitudes, aptitudes and behaviours in relation to sustainability; and ultimately in the extent to which they can transform themselves and society to become more sustainable. The purpose of this study was to devise and pilot a tool that could be used to profile sustainability competencies across a cohort of students in a higher education context. It is important to note that the remit of this study did not extend to uncovering reasons as to why certain dispositions, abilities or behaviours towards sustainability were present or absent, but rather to create a tool capable of generating a profile of learners' competencies at a particular point in time. The premise was that, if such a tool could be 
developed, then it could be utilised in future studies to identify the extent to which the sustainability-profiles of cohorts of students change over time in particular programmes of study in higher education. This could be used by future researchers to identify courses successfully fostering education for sustainable development, and thus, to explore in detail the types of pedagogic processes and practices resulting in improved sustainability competencies across cohorts of students.

The Dispositions, Abilities and Behaviours (DAB) framework that emerged presents a snapshot of a cohort of students' dispositions, abilities and behaviours vis-a-vis sustainability at a particular point in time. The discussion that ensues reports on the design, implementation and future developments with regards to the DAB framework. It begins by outlining the methodology for this pilot study, engages in a brief review of the literature on sustainability competencies, presents the DAB framework and ends with discussion of key findings from the study and implications for future research.

\section{Methodology}

This study used an explanatory mixed methods approach, which involved two phases of research to investigate the following questions:

1. What sustainability competencies can or should be assessed in higher education; and how should these competencies be framed?

2. Can students' development of these sustainability competencies (knowledge, skills, attitudes and/ or behaviours) be effectively measured within higher education?

The first phase involved the conceptualisation and design of the DAB framework, through qualitative data emergent from critical review of the literature and discussions with researchers and experts in sustainability education (SE). The second phase made use of a quantitative instrument (an online survey designed using elements of the DAB framework) that allowed learners to record their own perceived levels of sustainability competencies. The mixed method research approach thus involved the use of both quantitative and qualitative data collection and analysing tools.

The evolution of the DAB framework was informed by a review of the literature and discussions with experts in the domain of SE. In this regard, the qualitative data from both the literature review and conversations with experts were coded and emergent themes informed the data analysis process, which eventually resulted in the framing of sustainability competencies in terms of learners' dispositions, abilities and behaviours in sustainability (the DAB framework).

In terms of the quantitative dimension of this study, 37 students (out of a total of 95 ) in the final year of an undergraduate education programme in teacher education participated in an online survey modelled on the DAB framework. The majority of participants enrolled on the targeted degree course intended to qualify as primary-school teachers. There was a very high level of female participants within the course (circa $90 \%$ female), which was representative of the high proportion of females $(85 \%)$ engaged in initial primary teacher education more generally in Ireland (Central Statistics Office, 2012, p. 12).

According to Joppe (2000), as cited in Golafshani (2003), reliability (the extent to which an instrument's measurement results are consistent over time) and validity (the extent to which an instrument's results consistently measure the construct of interest) 
remain an important aspect of any research undertaking. Reliability and validity for this study were obtained through the use of the explanatory mixed methods approach. In this regard, the literature review on sustainability and sustainability competencies initially resulted in the authors' conceptualisation and design of the DAB framework. This DAB framework was then subjected to critical review at a number of seminars and conferences by experts and researchers within the field of sustainability, which helped to inform revisions to its design and establish its validity as a possible guide to designing a tool for assessing sustainability competencies. Secondly, based on a critical examination of the elements of the DAB instrument and themes generated from literature on sustainability and sustainability competencies, a survey instrument of 49 statements/questions was designed to measure students' sustainability competencies. The data generated from participants' responses on the survey questionnaire were analysed to better understand the extent to which the survey could be used to effectively profile sustainability competencies. The survey data were thus statistically analysed using the Statistical Package for Social Sciences (SPSS), Version 21, using statistical frequencies and internal consistency tests to ascertain construct validity.

Finally a triangulation process was employed, which involved the "mixing" of both the quantitative and qualitative research data of the study to better understand the research problem (Creswell, 2012), providing a more "complete picture" (Greene, Caracelli, \& Graham,1989) and ascertaining the overall validity of the study.

\section{Sustainability in Focus}

In the review of the literature that follows, the key concepts and contexts of education for sustainable development (ESD) are examined, beginning with exploration of the concepts of ESD, and then focusing on the area of sustainability competencies.

\section{Sustainability}

The concept of sustainability remains controversial with no universally acceptable definition. Generally sustainability is conceived as the ability to maintain something for a long time at a specific rate or level. It is an undefined set of ideals which allow people and other living and non-living things to have dignity and satisfaction and for human actions to be geared towards protecting the environment, fostering societal justice, economic prosperity and equity and promoting cultural vitality and diversity.

The World Commission on Environment and Development (WCED) report, also called the Brundtland Report, "Our Common Future", defined sustainable development as "development that meets the needs of the present without compromising the ability of future generations to meet their own needs" (WCED, 1987, p. 43). Since then, sustainable development has become a global catch phrase giving rise to a widening of the discourse of the concept with many definitions (Mebratu, 1998). This study will focus on this UN definition of the concept, which is widely accepted globally. The UN definition of sustainable development focuses on intergenerational equity and implies that there are limits on the carrying capacity of the environment "to absorb the effects of human activities" (Kates, Parris, \& Leiserowitz, 2005, p. 11). However, the concept of sustainable development remains heavily loaded with meanings and interpretations, vague and ambiguous, so much so that many scholars view the concept as an oxymoron - a 
concept that remains "fundamentally contradictory and irreconcilable" (Kates et al., 2005 , p. 20). In spite of the divergent definitions and criticisms, the concept of sustainable development is open to interpretations and adaptations to different socio-cultural, economic and ecological contexts.

\section{Education for Sustainability}

Education is crucial in fostering the ideals of sustainability. ESD is a process of learning how to make decisions that consider the long-term futures of the economy, ecology, the equitable development of all communities as well as the promotion of their cultures. ESD enables people to develop the knowledge, skills, values and competencies that promote sustainable actions and lead to improved quality of life now without destroying the environment for future generations. ESD provides individuals with the competencies to make judgements and choices towards more sustainable behaviours. People all over the world need the basic life necessities of employment, health, education, food, shelter and sanitation, which protects their quality of life. These necessities should be obtained while protecting and preserving the environment and ensuring that future generations will also have the opportunity to enjoy the same. The present global economic recession and the catastrophic impacts of climate change and other environmental hazards provide evidence of the unsustainable economic, financial and ecological actions of humanity. The impacts of such unsustainable human actions call for the need to promote a shift in human mindsets to embrace more sustainable values, behaviours and lifestyles which can make the world safer, healthier and more prosperous for all, thus improving both the environmental and human quality of life.

ESD is vital for human development. A vision of the United Nations Educational, Scientific and Cultural Organization (UNESCO, 2006) of sustainability centres on

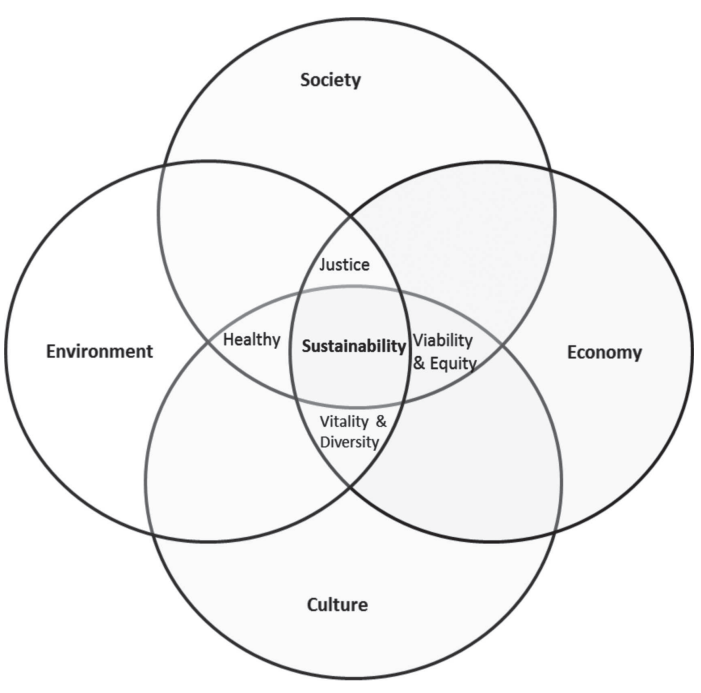

Figure 1. The four coner stones of sustainability education (Bangerter, Greer, Harich, Krause, \& Turner, 2014) developing a world where everyone has the opportunity to benefit from quality education and learn the values, behaviours and lifestyles required for a sustainable future and for positive societal transformation. ESD is thus a process of learning how to make decisions that consider the long-term effects of human actions on the environment, promoting diversity in cultures, values and beliefs, equitable and green economic development as well as societal justice.

SE is conceptualised as a holistic system with the four interconnected and interdependent components. These components: economy, society, culture and the environment are important in attaining sustainability. Any actions in one area have consequences on the other components be them positive or 
negative. According to Yencken \& Wilkinson (2001), the goal is to attain a positive balance on all the four components

In the context of this paper, the terms "education for sustainable development", "sustainability education" and "education for sustainability" are considered to mean one and the same thing, and are used interchangeably.

\section{Sustainability Competencies}

The concept of competence is complex, difficult to define and measure and has varied meanings in different contexts and areas of practice (FitzGerald, Walsh, \& McCutcheon, 2001; Levett-Jones, Gersbach, Arthur, \& Roche, 2011; Pedersen, 2007; Stevenson, 1996; Watson, Stimpson, Topping, \& Porock, 2002). The broader discourse of the concepts of competence and competency is beyond the scope of this paper, so this paper will focus on the concept of competence in relation to the practice of sustainability.

Gonczi (2002) argues that competency is inferred from performance and is not directly observable. Gonczi further explains that, while the activities an individual performs are observable, the attributes that underlie the performance are inferred. In this light, he argues that competency is the amalgamation of knowledge, skills, dispositions and values. Thus individuals' performances of tasks and activities "rests on more general capacities such as reasoning and making judgements as well as specific knowledge and individuals' dispositions" (Gonczi, 2002, p. 120). Therefore in viewing the concept of competence in this way, there is no dichotomy between specific competencies and key competencies, because the capacity to perform specific activities will always entail some combination of knowledge, skills and dispositions. This holistic and integrated approach is in line with the definition of sustainability competencies. In order to live sustainably, individuals need to develop capabilities to bring together a range of attributes, skills, knowledge, values and dispositions which promote sustainability actions in a given context. In this light, Wiek (2010) defines sustainability competencies as “complexes of knowledge, skills, and attitudes that enable successful task performance and problemsolving with respect to real-world sustainability problems, challenges, and opportunities" (n.p.). In the same light, Mochizuki and Fadeeva (2010) argue that competence is what learners are able to do at the end of a learning activity.

Within this paper, learner sustainability competencies are posited as action oriented and encompass the ability to perform. This position aligns with UNESCO's (1996) identified key competencies of education for the $21^{\text {st }}$ century as presented in the Delors report "Learning: The Treasure Within”, which identifies four key competencies in education which include: learning to know, learning to do, learning to be and learning to live together. These key competencies of education have been adopted as important pillars of sustainability competencies. In addition, a fifth cluster of sustainability competencies has been identified in the UN report (Shaeffer, 2007) which includes the sustainability competence of 'learning to transform oneself and society'. Together these five clusters of competencies encompass the five key sustainability competencies necessary for SE. 


\section{Measuring Sustainability Competencies}

An important aspect of SE is to identify the types of competencies necessary for educating learners in sustainability. However, there are difficulties in the area of evaluating or measuring learners' abilities and manifestations of acquired sustainability competencies, and this issue is the centrepiece of this study. Within existing literature in sustainability competencies, there are limited paradigmatic frameworks to guide educators in the process of evaluating the actual performances and/or manifestations of learners' sustainability competencies. Therefore, this study involved the conceptualisation, design and use of a sustainability competencies framework called the DAB framework as a guide in the development of a tool to test or measure learners' sustainability competencies in higher education. The development of this framework is needed to fill the paradigmatic vacuum, that is, the absence of a framework to guide educators in assessing learners' acquisition of sustainability competencies in SE. The discusssion now moves to describe the DAB framework.

\section{The DAB Framework}

As outlined earlier, this study examined two questions, the first of which is responded to here: What sustainability competencies can or should be assessed in higher education? and How should these competencies be framed? In this regard, the DAB framework of competencies emerged from the qualitative dimension of this pilot study. So, what does DAB mean?

The DAB framework refers to the dispositions, abilities and behaviours that learners' exhibit in relation to sustainability.

The Dispositions refers to learners' dispositions for sustainability and this includes: learners' desires/willingness and motivations to engage with sustainability and learners' attitudes, beliefs and value orientations in relation to sustainability. Learners' dispositions for sustainability relate to their sustainability competencies in 'Learning to be' and 'Learning to live together' (UNESCO, 1996). Learners' values-orientations, belief-systems and attitudes, influence their desires, motivations and willingness to engage with sustainability. The impact of worldviews on engagements with sustainability is vividly explained in Escobar's (2001) arguments that communities actively construct their sociocultural worlds "through their laborious daily practices of being, knowing, and doing ... even if in the midst of other forces." (p. 153). Cultural constructs and contexts thus impact on learners' desires and motivations to engage with sustainability.

The Abilities refers to learners' abilities in sustainability, including learners' skills, aptitudes and knowledge for action on sustainability. Learners' abilities to engage with sustainability relate to their sustainability competencies in learning to know and to do (UNESCO, 1996), and this involves learners' cognitive capabilities and skills to engage in thinking that reflects sustainability values. This involves learners' development of cognitive capabilities for systemic thinking, strategic planning, critical reflection, values thinking and futures thinking for sustainability.

The Behaviours refers to learners' behaviours in relation to sustainability. Learners' behaviours to promote sustainability relates to their sustainability competencies in 'learning to transform oneself and society' (Shaeffer, 2007). This involves their manifestations of sustainability through the actual actions taken to embrace or foster sustainability, thus acting as change agents for sustainability. 
The DAB framework (Figure 2) is thus a guide towards understanding the key areas in which sustainability competencies can be measured as explained below:

1. assessing learners' dispositions with regard to sustainability (which involves the process of assessing whether learners' values, attitudes and beliefs are oriented towards promoting sustainability values like promoting environmental health, social inclusion and justice, intercultural communication, acceptance and preservation of indigenous knowledge);

2. assessing learners' abilities to foster sustainability (which includes assessing whether learners have acquired the requisite cognitive skills in systemic thinking, strategic planning, critical reflection, values thinking and futures thinking as well as skills, aptitudes and knowledge in sustainability);

3. Assessing learners' behaviours in relation to sustainability (which includes assessing the actual actions carried out by learners to act as change agents for promoting sustainability).

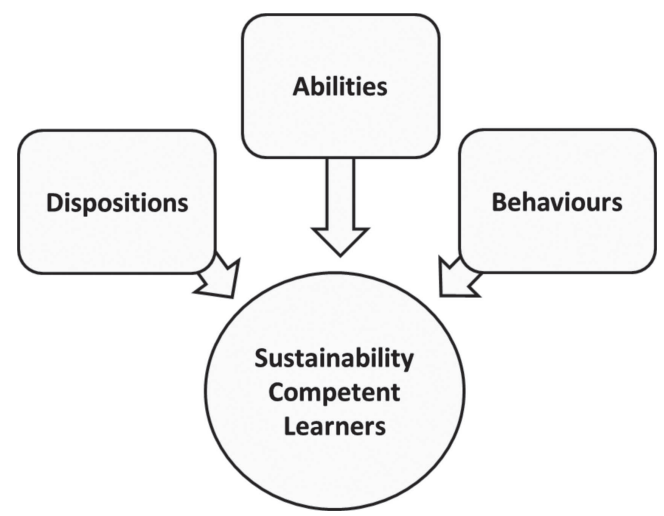

Figure 2. Dispositions, Abilities and Behaviours (DAB) Framework

\section{Assessing Learners'Sustainability Competencies Using the DAB Framework}

The second part of this study focused on exploring the question: Can students' development of these sustainability competencies (knowledge, skills, attitudes and/ or behaviours) be effectively measured within higher education? In this regard, the assessment of sustainability competencies was considered through the lens of the DAB framework, sustainability competencies (Learning to Know; Learning to Do; Learning to Be; Learning to Live Together and Learning to Transform Oneself and Society) and key sustainability thematic areas.

The DAB framework informed the design of an online survey, which took the form of a set of context specific sustainability-related statements or questions used to ascertain learners' dispositions, abilities and actions in fostering sustainability. This online survey was designed in such a way that it addressed the four cornerstones of sustainability, as well as the five clusters of sustainability competencies (Learning to Know; Learning to Do; Learning to Be; Learning to Live Together and Learning to Transform Oneself and Society). The set of questions and statements were used by learners' to record their perceived levels of sustainability competencies, and the data gathered were analysed in a process that involved mapping the cumulative attitudes, aptitudes (including skills 
and knowledge) and behaviours identified within the DAB framework. Thus the following criteria were taken into account within the mapping process:

1. the level of learners' agreements with and willingness to engage with sustainability issues/actions (mapping out learners' dispositions - attitudes, beliefs and value orientations - in relation to sustainability);

2. the level of learners' abilities to engage with sustainability issues/ actions (mapping out learners' aptitudes, skills and knowledge in sustainability);

3. the frequency of learners' engagements in actions for sustainability (mapping out actual actions carried out by learners to promote sustainability - by acting as champions or agents of change for sustainability).

The pilot survey was tested initially in November 2013 with a small sample of nine students to ascertain any issues with phrasing of statements or questions and/ or examine whether it could be completed within an appropriate time-frame. In light of this, a number of statements/questions were re-phrased and a number of questions deleted. The final version of the online survey of 49 questions was designed and structured into four areas examining the participants' profile, dispositions in relation to sustainability, abilities in sustainability and behaviours. The online survey was deployed in March 2014 (using the online software tool - Surveymonkey) to 95 final year higher education students in a higher education institution. A sample of 37 students in total responded to the survey (response rate of 39\%); their responses were collated using Surveymonkey, and the resultant data were then analysed using SPSS, version 21.

The participants varied in gender age, and types of study programmes. The gender breakdown of the 37 respondents was $84 \%(n=34)$ female and $16 \%(n=3)$ male. In terms of age, $70 \%$ were between 16 to 24 years and $30 \%$ were over 25 years. In relation to the study programmes, $16 \%$ of the participants were studying part time, and $84 \%$ were studying full time. In post-survey discussions, students cited the following reasons for non-participation in the survey: difficulties associated with meeting survey deadlines and assignment deadlines; lack of knowledge about the purpose of survey (which was in part due to low attendance at scheduled informational sessions on research study); pressures associated with being in their final year of study at university and a lack of interest for some students in the thematic area of this study.

As the response rate in this study was relatively small, few statistical methods could be applied to analyse the survey data. Consequently, there were limited statistical tests that could be carried out to test the statistical significance of the various sustainability items examined. In this case, a Cronbach's alpha test was used to validate the question scales and a Cronbach's alpha coefficient of .83 was obtained, indicating good internal consistency of themajority of the cases.

Data gathered from the pilot online survey were analysed using the following scales: Gender; Age; Study Programme; Course Years; Agreement with Sustainability Issues; Ability to Engage with Sustainability; Willingness to Engage with Sustainability Issues and Frequency of Actions Taken to Promote Sustainability.

- Gender was coded on a two-point scale (female $=1$, male $=0$ ), with predominately female respondents $(92 \%, \mathrm{n}=34)$ and males $(8 \%, \mathrm{n}=3)$.

- Age was coded on a two-point scale $(16-24=1,>25=0)$ the majority of the participants were between the ages of $16-24(70 \%, n=26)$ and 11 participants were 25 years and over accounting for $30 \%$. 
- Course Year was coded on a two-point scale using the following categories (Years 1 and $2=0$, Years 3 and $4=1$ ). 37 participants from third year undergraduate studies $(100 \%)$ responded to the pilot survey with a mean of .89 and the standard deviation of .315

- Study Programme was coded on a two-point scale, based on category of $(1=$ full time, 0 = flexible mode). There were six participants studying part time $(16 \%)$ and 31 participants studying full time $(84 \%)$.

In terms of the key focus of this study on sustainability, a number of key scales for assessing levels of sustainability competencies were created based on combining a number of question items, as discussed below.

\section{Willingness}

Summary statistics from 7 questions were used to evaluate learners' dispositions willingness to engage with sustainability. Willingness or learners' dispositions was coded as follows: 1 = willing, $0=$ not willing. The cumulative mean of .78 and the standard deviation of .307 , with a higher mean statistic, indicates a greater dispersion in pattern for those willing to engage with sustainability and those who were not willing to engage with sustainability issues.

\section{Abilities}

21 questions were used to ascertain learners' abilities to engage with sustainability actions/issues. Ability was coded as follows: $1=$ able, $0=$ not able. The survey results produced a cumulative mean of .63 and the standard deviation of .454 and a Cronbach's alpha coefficient of .83 indicating good internal consistency of scale for the 16 items used.

\section{Frequency of Action to Promote Sustainability}

The summary statistics for the 7 questions that evaluated the frequency of actions taken by learners as manifestations of competencies in change agency for sustainability were used to ascertain the frequency of action to promote sustainability. The responses were coded as follows: $1=$ at least once; $0=$ Not at all. The cumulative mean $=.54$; the standard deviation $=.498$, indicating that a moderate standard deviation of almost .50 , shows a slightly even dispersion in the pattern of learners' frequency of actions taken or not taken to promote sustainability. The results for the seven question items examined also produced a Cronbach's Alpha coefficient of .81 indicating good internal consistency of scale used.

\section{Agreement with Sustainability Issues}

Respondents recorded their level of agreement/ disagreement with 13 statements on sustainability issues and these responses were coded as follows: 0 = agreement, $1=$ disagreement. The initial premise was that agreement with a statement indicated a negative disposition towards sustainability, and disagreement with the statement indicated a positive disposition towards sustainability. These 13 items were summed, with a cumu- 
lative mean of .86 and the standard deviation of .334 with a low the standard deviation indicating less dispersion in the response patterns for this competence, and this is in line with the fact that the majority of respondents disagreed with most of the statements stated, thus indicating a high level of sustainability competencies on the 13 issues examined. A Cronbach's alpha of .70 suggests that the scale for these 13 items has good internal consistency. However, it is important to note here that because of a lack of sufficient statistical evidence to test statistical significance, this result is to be viewed cautiously.

\section{Key Findings on Sustainability Competencies}

The results of the pilot survey show that cumulatively a high percentage of learners exhibited competencies in the areas of sustainability that were examined.

An important dimension of 'Dispositions' towards sustainability can be examined in learners' willingness to engage in sustainability behaviours and/or actions. Figure 3 illustrates respondents' willingness/unwillingness to engage in specific inclusive, participatory and authentic actions for sustainability. As far as the willingness to engage with sustainability is concerned, the survey results show that on average $87 \%$ of respondents were willing to engage with sustainability and thus have a high level of disposition to do so, while only $13 \%$ on average of the respondents lacked the disposition to engage with sustainability thus manifesting a very low level of disposition for sustainability.

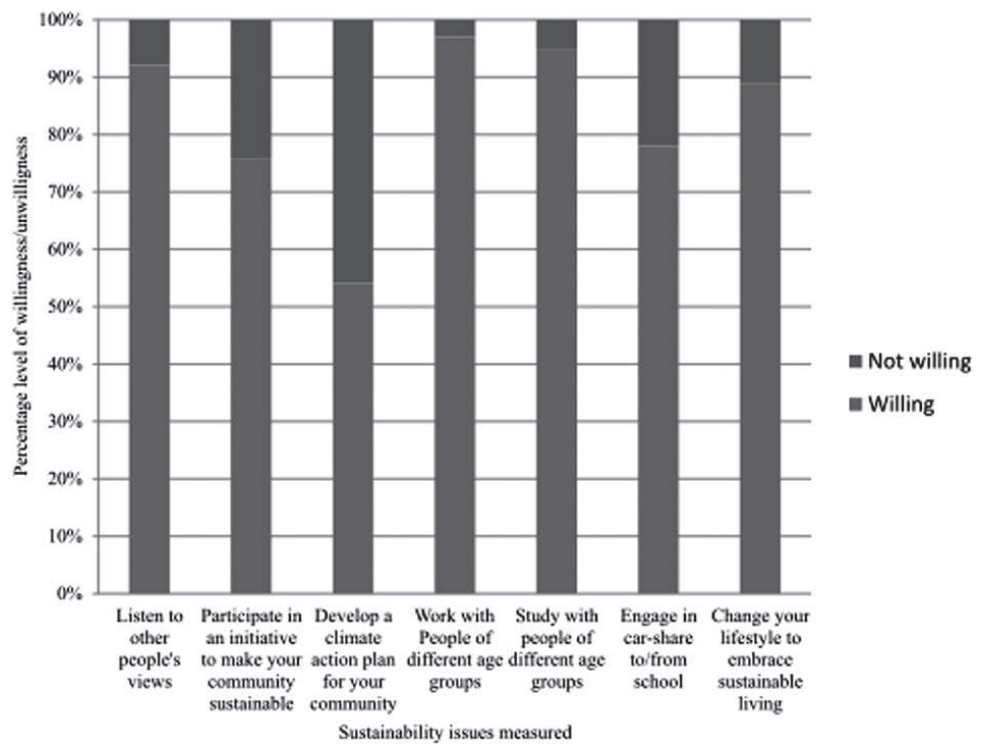

Figure 3. Dispositions: Willing/not willing to engage with sustainability

The participants were also asked to rate their 'Abilities' to perform sustainabilityrelated activities. Figure 4 illustrates respondents' perceived levels of ability to engage in various sustainability actions. In relation to this, results from the survey show that cumulatively $45 \%$ of the learners on average perceived themselves as having low abilities to engage with sustainability, while $55 \%$ on average perceived themselves as having good abilities to engage with sustainability. 


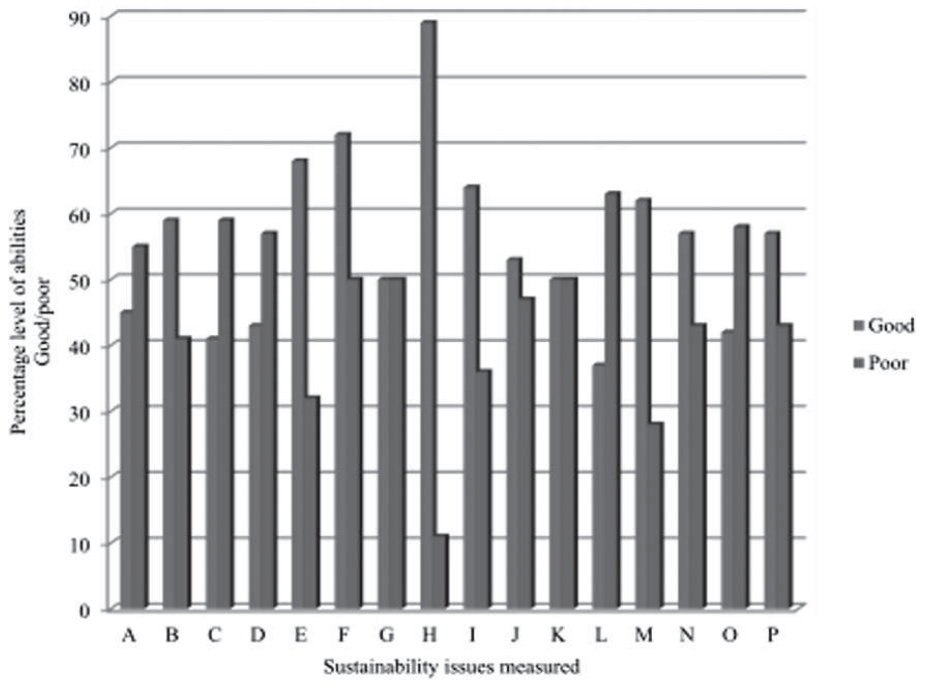

Key

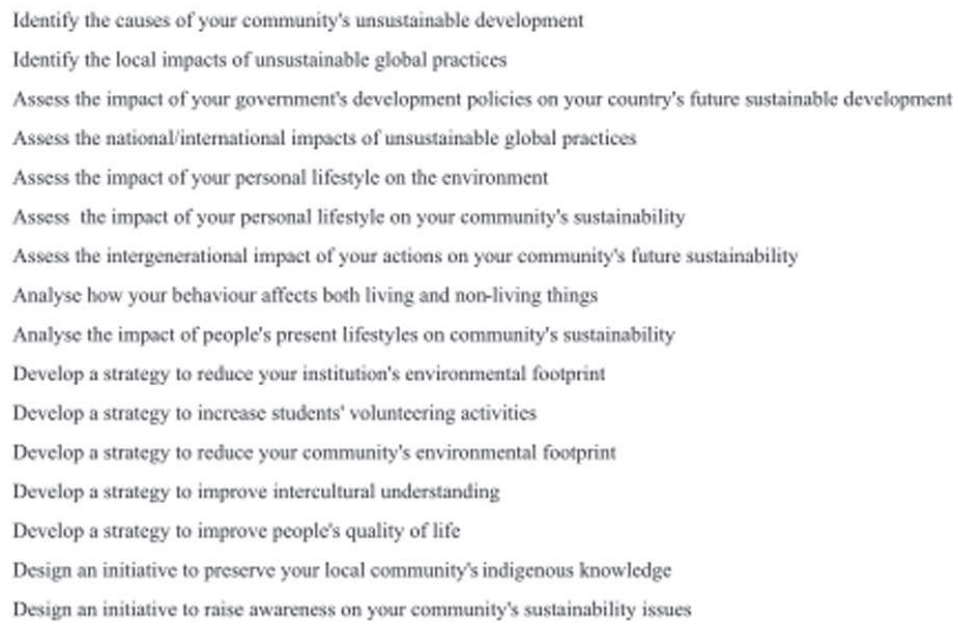

Figure 4. Abilities: Perceived levels of abilities to engage with sustainability issues

In relation to actions for sustainability - 'Behaviours', the respondents indicated on a frequency scale their level of engagement in sustainability actions. Figure 5 illustrates the frequency with which respondents engaged in sustainability actions (Figure 5 see on next page). As far as the frequency in which learners take actions to promote sustainability, the survey results show that on average $49 \%$ of the respondents have taken actions at least once in a week, month or year to promote sustainability, thus acting as change agents and manifesting some level of sustainability competencies for change agency; while $51 \%$ of learners on average have not taken any actions to promote sustainability which could be suggestive of a negative disposition or low level of ability in the competence of change agency.

Thus, when the results of the pilot study are viewed through the lens of the DAB framework we can conclude that overall this sample group were very positively disposed towards sustainability (Dispositions), almost half of them felt they lacked skills/abilities 
to perform particular sustainability actions (Abilities), and that there existed very close to a 50-50 split in students engaged/ not engaged in sustainability actions (Behaviours). Further research would be required to investigate the disjoint between the very high degree of willingness to engage in sustainability ( $87 \%$ on average across this cohort of students) and the lower levels of action for sustainability (circa $50 \%$ on average).

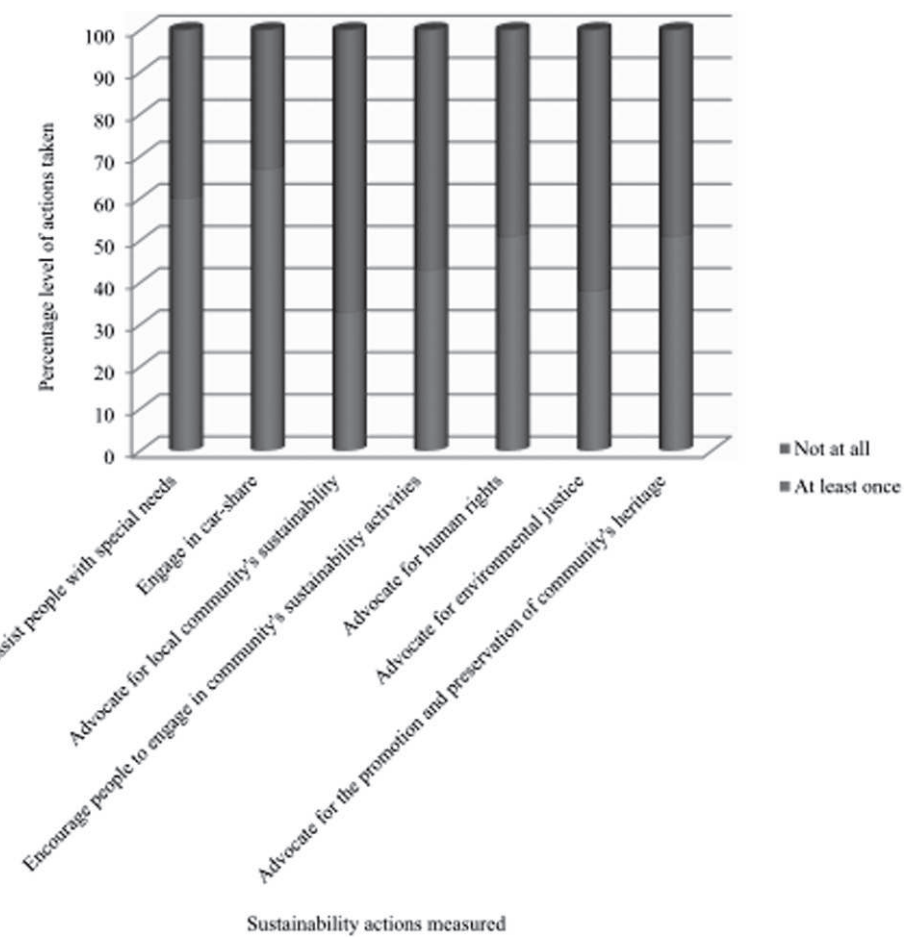

Figure 5. Behaviours: Frequency of actions taken for sustainability

Finally, the initial intention was that the dimension of Dispositions in sustainability would also be examined or informed by learners' considerations of a set of statements on key sustainability issues; their responses were ranked on a scale from 1 to 5 , indicating their level of agreement or disagreement. For instance, dumping waste in the seas and oceans is acceptable. Figure 6 illustrates the respondents' level of agreement/disagreement with specific perspectives or stances on sustainability.

The data analysed from this section of the survey indicated that the majority of the learners, with a cumulative average response of $83 \%$ disagreeing with the statements, displayed critical awareness of the sustainability issues examined; while the minority of learners, $17 \%$ of the respondents on average agreeing with the sustainability statements, displayed a lack of knowledge of or appreciation for sustainability issues. However, it cannot be concluded that there is a direct correlation between the levels of agreement or disagreement to statements on this survey and negative or positive dispositions towards sustainability as this would involve making presumptions about the levels of and relationships between, knowledge and dispositions of learners. As a result of this ambiguity, in analysing responses to these statements, it has been decided that future manifestations of the online survey will not include this section. 


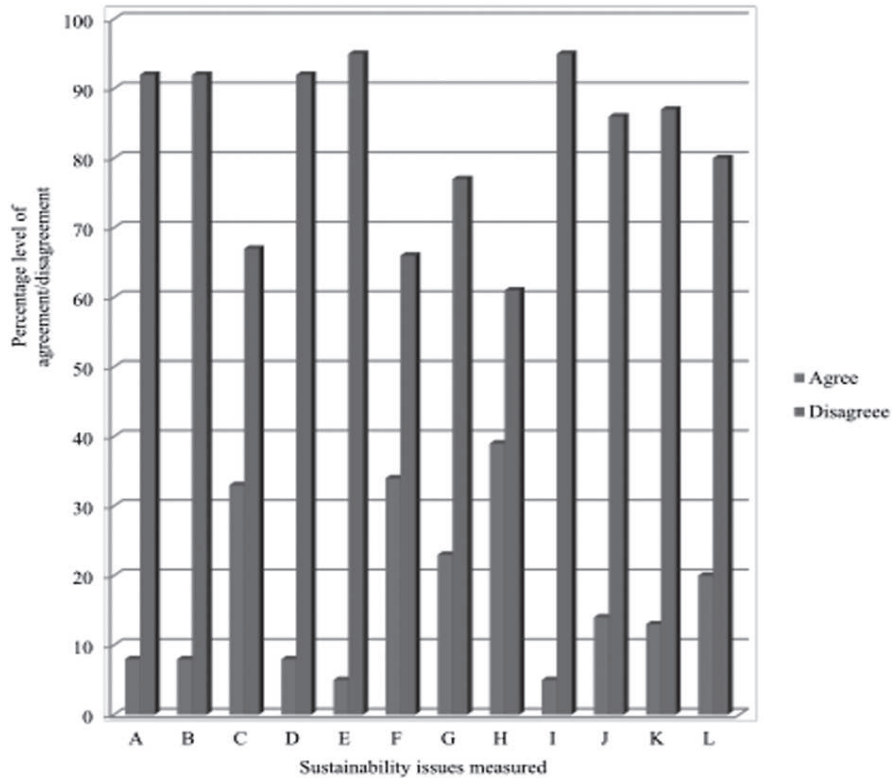

Key
A: Environmental conservation is only the third world countries' conoem
B: Dumping waste in the sea is acceptable
C: Emerging economies should overexploit their natural resources
D: It is acceptable to overexploit fossil fuels
E: Economic globalisation has no effects on local economies
F: Personal comfort should be prioritised over environmental conoems
G: Nature's purpose is to serve human noeds
H: Globalisationhas no impact on local cultures
I: All the talk about climate change is politicking
J: Climate change is not impactod by human actions
K: Individuals cannot counter climate change
L: $\quad$ The quality of the environment has no impact on human quality of life

Figure 6. Perspectives on sustainability issues

\section{Discussion}

The overall findings of this study present a good snapshot of higher education learners' sustainability competencies and how these students' sustainability competencies can be profiled at a given point in time. Despite the limitations in the number of learners who responded to the study questionnaire, the findings of this study present us with important lessons to learn with regard to higher education learners' dispositions, abilities and behaviour (actions) with regard to engaging with sustainability related challenges.

The study findings show that despite the provisions of extensive information and awareness campaigns on environmental matters (for instance, through campus greening initiatives), many higher education learners (46\%), as shown in Figure 3, are not willing to develop climate actions plans for their communities. Also, over $63 \%$ of the learners 
do not have the abilities to develop a strategy to reduce the future environmental footprints of their local communities as shown in Figure 4. The same situation is exhibited in the fact that well over $68 \%$ of the learners did not take actions to advocate for their local community sustainability, and over $62 \%$ of them did not take any actions to advocate for environmental justice as shown in figure 5 .

These findings clearly indicate that despite general awareness on environmental matters there is the need to mainstream climate change education in higher education curricula so as to provide learners with the knowledge, skills and competencies to carry out strategic planning for climate change actions and natural disaster mitigation to make their communities more resilient and sustainable.

Another important aspect of sustainability which the study findings present is the issue of learners' value orientations in relation to sustainability. The study findings show that with regard to sustainability values like car-sharing when travelling to work or to school, the majority of higher education learners surveyed (78\%), as shown in Figure 3, are willing to engage in car-share to school or work. This finding is a good pointer to the fact that present-day higher education learners are beginning to realise the need to reduce the volume of carbon dioxide emitted into the atmosphere through the increased volumes of automobiles on our roads. These students' values orientations suggest alignment with some key sustainability values; in this case, their willingness to engage in carsharing when travelling to school or work. However, a small percentage of the students surveyed $(22 \%)$ still nurture the values of prosperity, viewed in terms of wealth and property accumulation. Thus these learners cherish the comfort of enjoying single occupancy of their cars to travel to school or work if they have the means to do so, instead of engaging in car-share, even if they are aware of the benefits to the atmosphere of reduced carbon emissions through the reduction in the volume of automobiles on our roads.

Furthermore, the majority of the learners (95\%) disagreed with the statement 'All the talk about climate change is politicking, and there is no real need to take action'. Despite vigorous campaigns by contrarians (especially multinational oil corporations which consider corporate profiteering to be of prime importance over environmental concerns), there is enormous scientific evidence that increasing global temperatures are a threat not only to the environment but also to human societies (Pachauri \& Meyer, 2014). These learners' responses suggest recognition of the fact that climate change is a serious issue that needs to be addressed.

As outlined earlier, there are currently no paradigmatic frameworks to guide educators in assessing higher education learners' sustainability competencies, although there is growing interest and calls for integrating sustainability across higher education curricular (Benn \& Dunphy, 2009; Hopkinson \& James, 2010; Makrakis \& KostoulasMakrakis 2013;). In terms of assessing sustainability-related knowledge, skills, dispositions and behaviours, there have been many attempts to develop scales, mainly within the context of environmental education. The most well known of these is the Dunlap and Van Liere's (1978) New Environmental Paradigm Scale (original NEP), a 12 -item scale for ascertaining when populations in transition to more environmentally conscious worldviews, which was subsequently reviewed, revised and renamed by the Dunlap and his colleagues to become a 15-item Revised New Ecological Paradigm Scale (Dunlap, Van Liere, Mertig, \& Jones, 2000). Other scales include the Ecocentric and Anthropocentric Attitudes towards Sustainable Development (EAATSD) scale, which is used to evaluate students' perception of relationship between environmental and 
social issues (Kopnina, 2013), and the Sustainability Tracking and Rating System (STARS), a tool developed by the Association for the Advancement of Sustainability in Higher Education (AASHE, 2012) for assessing both learners' and staff sustainability knowledge and activities. However, the STARS and similar tools are principally designed to assess higher education campus greening activities and are thus not appropriate tools for undertaking a holistic assessment, or in profiling, of learners' sustainability competencies.

More recently, Zwickle, Koontz, Slagle and Bruskotter (2014) designed a multiple choice survey as a tool for assessing higher education students' sustainability knowledge and used statistical analysis to present the results of their survey. However, in the absence of articulation of what was understood as sustainability knowledge and what sustainability criteria underpinned the design of the tool, it is difficult to critically engage in an analysis of their findings. Interestingly, the study of Zwickle et al. (2014) also highlights the difficulties of engaging higher education learners in responding to online surveys on SE in general and assessment of learners' sustainability knowledge and competencies in particular. The authors explain that their university-wide survey to assess students' sustainability knowledge with a sample of more 40000 undergraduate students enrolled in Ohio State University in the United States of America had a response rate of only 1,389 students $(13.3 \%$ of their sample). In comparison to their limited response rate, the response rate in the $\mathrm{DAB}$ study of $38 \%$ looks very healthy, although the overall target group for the DAB pilot study was very small when compared to their study.

\section{Conclusions}

Changes in human behaviours to embrace sustainability can be activated through formal, non-formal and informal educational processes. Higher education institutions have an important role to play as drivers of education, training and policy enhancement for sustainability. As advocated in the University Charter for Sustainable Development (Copernicus, 1994), the Talloires Declaration (2005), the UN Decade of Education for Sustainable 2005-2014 (UNESCO, 2007) and the Council of the European Union's (2011) strategic framework for European cooperation in education and training 2020, universities and other higher education institutions are called upon to play a critical role in mobilising and fostering learners' acquisition of sustainability competences. Higher education institutions have the expertise to foster the knowledge and skills necessary to enable students devise preventative strategies and/or solutions to sustainability related issues now and in the future. In this regard, the DAB framework emergent from this study comes at an important juncture for higher education. It offers higher education institutions, educators and/or researchers opportunities to better understand the nature and extent of competencies development (with respect to sustainability-related abilities, attitudes and actions) within higher education. The findings of this pilot study show that the online survey tool can be used by educators to profile learners' sustainability competencies in higher education and provides a useful snapshot of their perceived competencies with respect to sustainability at particular point/s in time.

Finally, as outlined previously, the results of this pilot study need to be cautiously considered because of the small size of the sample. This pilot study mainly intended to inform us on the reliability and internal construct consistency of the DAB-informed sustainability competencies survey tool, ahead of its deployment on a university-wide basis in 2015. Data from the university wide survey in 2015 will be subjected to a 
thorough and rigorous statistical analysis, since the survey will be deployed with a much larger sample of students, with the expectation of much higher participation levels of students). In terms of encouraging participation, the large-scale deployment of DAB survey tool (and corresponding informational events about the research study) will be time-tabled to ensure that there are no conflicts with assignment deadlines. Furthermore, more emphasis will be placed on the benefits of engagement in the survey (such as opportunities to informSE) in the informational events with students. This future study will thus examine whether the DAB-informed survey tool can be used as an instrument to profile sustainability competencies across cohorts of students in a range of disciplinary and trans-disciplinary contexts across their life-span of higher education.

\section{References}

Association for the Advancement of Sustainability in Higher Education (AASHE). (2012). STARS: A program of AASHE: Version 1.2 Technical Manual. Retrieved from http://www.aashe.org/files/documents/STARS/stars_1.2_technical_manual.pdf

Benn, S., \&Dunphy, D. (2009). Action research as an approach to integrating sustainability in MBA programs: An exploratory study. Journal of Management Education, 33(3), 276-295.

Central Statistics Office. (2012). Women and men in Ireland. Dublin: Stationary Office.

Copernicus. (1994). The University Charter for sustainable development. Retrieved from http://www.iids.org/educate/declarat/coper.htm

Council of the European Union (2011). The role of education and training in the implementation of the 'Europe 2020'Strategy. Conclusions of the Council. Retrieved from http://ec.europa.eu/education/lifelong-learning-policy/policy-framework_ en.htm

Creswell, J. W. (2012). Educational research: Planning, conducting, and evaluating quantitative and qualitative research ( $4^{\text {th }}$ ed.). Boston: Pearson.

Dunlap, R. E., \& Van Liere, K. D. (1978). The "new environmental paradigm": A proposed measuring instrument and preliminary results. Environmental Education, 9, 10-11.

Dunlap, R. E., Van Liere, K. D., Mertig, A. G., \& Jones, R. E. (2000). Measurement endorsement of the new ecological paradigm: A revised NEP scale. Journal of Social Issues, 56(3), 425-442.

Escobar, A. (2001). Culture sits in Places: Reflections on globalism and subaltern strategies of localization. Journal of Political Geography, 20(2), 139-174.

FitzGerald, M., Walsh, K., \& McCutcheon, H. (2001). An integrative systematic review of indicators for competence for practice and protocol for validation of indicators of competence. Brisbane: The Queensland Nursing Council.

Golafshani, N. (2003). Understanding reliability and validity in qualitative research. The Qualitative Report, 8(4), 597-606.

Gonczi, A. (2002). Teaching and learning of the key competencies. In D. S. Rychen, L. H. Salganik \& M. E. McLaughlin (Eds.), Definition and selection of key competencies. Contribution to the second DeSeCo symposium. Retrieved from http://www.deseco.admin.ch/bfs/deseco/en/index/02.parsys.26255.downloadList. 54824.DownloadFile.tmp/2003.symposiumvolume.pdf 
Greene, J. C., Caracelli, V. J., \& Graham, W. F. (1989). Towards a conceptual framework for mixed-method evaluation designs. Journal of Educational Evaluation and Policy Analysis, 11, 255-274.

Hopkinson, P., \& James, P., (2010). Practical pedagogy for embedding ESD in science, technology, engineering and mathematics curricula. International Journal of Sustainability in Higher Education,11(4), 365-379.

Kates, R. W., Parris, T. M., \& Leiserowitz, A. A. (2005). What is sustainable development? Goals, indicators, values and practice. Journal of Environment, Science and Policy for Sustainable Development, 47(3), 8-21.

Kopnina, H. (2013). Evaluating education for sustainable development (ESD): Using ecocentric and anthropocentric attitudes toward the sustainable development (EAATSD) scale. Journal of Environment, Development and Sustainability, 15(3), 607-623.

Levett-Jones, T., Gersbach, J. Arthur, C., \& Roche, J. (2011). Implementing a clinical competency assessment model that promotes critical reflection and ensures nursing graduates' readiness for professional practice. Nurse Education in Practice, 11(1), 64-69.

Makrakis, V., \& Kostoulas-Makrakis, N. (2013). A methodology for reorienting university curricula to address sustainability: The RUCAS-Tempus project initiative. In C. Jabbour, S. Caeiro, U. M. Azeiteiro \& W. L. Filho (Eds.), Sustainability assessment tools in higher education institutions - mapping trends and good practices around the world (pp. 323-358). London: Springer. doi: 10.1007/978-3-319-02375-5

Mebratu, D. (1998). Sustainability and sustainable development: Historical and conceptual review. Environmental Impact Assessment Review, 18, 493-520.

Mochizuki, Y., \& Fadeeva, Z. (2010). Competences for sustainable development and sustainability: Significance and challenges for ES. International Journal of Sustainability in Higher Education, 11(4), 391-403.

Pachauri, R. J., \& Meyer, L. (2014). Climate change 2014 synthesis report: Summary for policy makers. Retrieved from http://www.ipcc.ch/pdf/assessment-report/ar5/ syr/SYR_AR5_SPMcorr1.pdf

Pedersen, P. B. (2007). Ethics, competence, and professional issues in cross-cultural counseling. Retrieved from http://www.sagepub.com/upm-data/15654_ Chapter_1.pdf

Shaeffer, S.(2007). Education for sustainable development: A framework for reform. Retrieved from http://www.unescobkk.org/esd

Stevenson, J. (1996). The metamorphosis of the construction of competence. Studies in Continuing Education, 18(1), 24-42.

Talloires Declaration. (2005). Talloires Declaration on the civic roles and social responsibilities of higher education. Retrieved from http://talloiresnetwork.tufts.edu/whatis-the-talloires-network/talloires-declaration/

United Nations Educational, Scientific and Cultural Organisation (UNESCO). (1996). Learning - the treasure within. Paris: UNESCO.

United Nations Educational Scientific and Cultural Organisation (UNESCO). (2006). UNESCO's role, vision and challenges for the UN Decade of Education for Sustainable Development (2005-2014). Retrieved from http://unesdoc.unesco.org/images/ 0014/001469/146976e.pdf 
United Nations Educational Scientific and Cultural Organisation (UNESCO). (2007). The UN Decade for Education for Sustainable Development 2005-2014. Retrieved from http://unesdoc.unesco.org/images/0015/001540/154093e.pdf

USA Department of the Interior University. (2013). Career development: Competencies. Retrieved from http://www.doiu.doi.gov/competencies

Watson, R., Stimpson, A., Topping, A., \& Porock, D. (2002). Clinical competence in nursing: A systematic review of the literature. Journal of Advanced Nursing, 39(5), 421-431.

Wiek, A. (2010). Sustainability science - what are the core competencies? Retrieved from http://icss2010.net/download/documents/24-JUNE/Sessione-5_Sustainabilityscience-education

World Commission on Environment and Development (WCED). (1987). Our common future: Report of the World Commission on Environment and Development. Oxford: Oxford University Press.

Yencken, D., \& Wilkinson, D. (2001). Resetting the compass: Australia's journey towards sustainability. Collingwood, Victoria: Csiro Publishing.

Zwickle, A., Koontz, T. M., Slagle, K. M., \& Bruskotter, J. T. (2014). Assessing sustainability knowledge of a student population: Developing a tool to measure knowledge in the environmental, economic and social domains. International Journal of Sustainability in Higher Education, 15(4), 375-389.

Correspondence concerning this paper should be addressed to Frida Besong, a PhD candidate, School of Education Studies, Dublin City University, Glasnevin, Dublin 9, Ireland. Email: frida.besong2@mail.dcu.ie 